\title{
Effectiveness of SmartMoms, a Novel eHealth Intervention for Management of Gestational Weight Gain: Randomized Controlled Pilot Trial
}

Leanne M Redman ${ }^{1}, \mathrm{MSc}, \mathrm{PhD}$; L. Anne Gilmore ${ }^{1}$, PhD; Jeffrey Breaux ${ }^{2}$, MD; Diana M Thomas ${ }^{3}, \mathrm{PhD}$; Karen Elkind-Hirsch ${ }^{2}, \mathrm{MSc}, \mathrm{PhD}$; Tiffany Stewart ${ }^{1}, \mathrm{PhD}$; Daniel S Hsia ${ }^{1}, \mathrm{MD}$; Jeffrey Burton ${ }^{1}, \mathrm{MSc}, \mathrm{PhD} ; \mathrm{John}_{\mathrm{W}}$ Apolzan ${ }^{1}$, PhD; Loren E Cain ${ }^{1}$, MS; Abby D Altazan ${ }^{1}$, MS; Shelly Ragusa ${ }^{1}$, MS, RD, CDE; Heather Brady ${ }^{1}$, MS; Allison Davis ${ }^{1}$, MS; J. Mick Tilford ${ }^{4}$; Elizabeth F Sutton ${ }^{1}$, PhD; Corby K Martin ${ }^{1}$, PhD

\footnotetext{
${ }^{1}$ Pennington Biomedical Research Center, Baton Rouge, LA, United States

${ }^{2}$ Woman's Hospital, Baton Rouge, LA, United States

${ }^{3}$ United States Military Academy, West Point, NY, United States

${ }^{4}$ University of Arkansas for Medical Sciences, Little Rock, AR, United States
}

Corresponding Author:

Leanne M Redman, MSc, PhD

Pennington Biomedical Research Center

6400 Perkins Road

Baton Rouge, LA, 70808

United States

Phone: 12257630947

Fax: 17633030

Email: leanne.redman@pbrc.edu

\section{Abstract}

Background: Two-thirds of pregnant women exceed gestational weight gain (GWG) recommendations. Because excess GWG is associated with adverse outcomes for mother and child, development of scalable and cost-effective approaches to deliver intensive lifestyle programs during pregnancy is urgent.

Objective: The aim of this study was to decrease the proportion of women who exceed the Institute of Medicine (IOM) 2009 GWG guidelines.

Methods: In a parallel-arm randomized controlled trial, 54 pregnant women (age 18-40 years) who were overweight (n=25) or obese $(n=29)$ were enrolled to test whether an intensive lifestyle intervention (called SmartMoms) decreased the proportion of women with excess GWG, defined as exceeding the 2009 IOM guidelines, compared to no intervention (usual care group). The SmartMoms intervention was delivered through mobile phone (remote group) or in a traditional in-person, clinic-based setting (in-person group), and included a personalized dietary intake prescription, self-monitoring weight against a personalized weight graph, activity tracking with a pedometer, receipt of health information, and continuous personalized feedback from counselors.

Results: A significantly smaller proportion of women exceeded the IOM 2009 GWG guidelines in the SmartMoms intervention groups (in-person: $56 \%, 10 / 18$; remote: $58 \%, 11 / 19)$ compared to usual care $(85 \%, 11 / 13 ; P=.02)$. The remote intervention was a lower cost to participants (mean US \$97, SD \$6 vs mean US \$347, SD \$40 per participant; $P<.001$ ) and clinics (US \$215 vs US $\$ 419$ per participant) and with increased intervention adherence $(76.5 \%$ vs $60.8 \% ; P=.049)$.

Conclusions: An intensive lifestyle intervention for GWG can be effectively delivered via a mobile phone, which is both cost-effective and scalable.

Trial Registration: Clinicaltrials.gov NCT01610752; https://clinicaltrials.gov/ct2/show/NCT01610752 (Archived by WebCite at http://www.webcitation.org/6sarNB4iW)

(JMIR Mhealth Uhealth 2017;5(9):e133) doi: 10.2196/mhealth.8228

\section{KEYWORDS}

pregnancy; gestational weight gain; lifestyle modification; intervention 


\section{Introduction}

More than two-thirds of pregnant women exceed the Institute of Medicine (IOM) 2009 gestational weight gain (GWG) recommendations [1]. According to weight management guidelines for obesity treatment [2], prenatal care should provide an ideal clinical framework for treatment delivery with frequent visits, weight recording, an established definition of acceptable weight gain, and opportunities for in-person counseling. However, despite several efforts to prevent excessive GWG in clinical trials, it remains unclear if lifestyle interventions can be efficacious, particularly in women with overweight or obesity $[3,4]$. Poor effectiveness in these trials is explained by intervention designs that fail to take advantage of the entire prenatal care continuum because program initiation is often delayed until mid or late gestation and weight management counseling and intervention are limited to one or two in-person sessions [3]. As more patients have access to mobile phones and $67 \%$ of pregnant women subscribe to electronic health information delivery during pregnancy [5], eHealth interventions designed to target healthy weight gain provide an opportunity for high-intensity and cost-effective interventions to be delivered to all patients throughout prenatal care. The aim of this study was to test whether a personalized gestational weight management program (SmartMoms) delivered in-person or via an intensity-matched mobile phone app could decrease the proportion of women with overweight and obesity that exceed the IOM 2009 guidelines for GWG by $25 \%$.

\section{Methods}

This study targeted overweight and obese (body mass index [BMI] 25.0-39.9 kg/m ${ }^{2}$ ) women aged 18 to 40 years expecting a singleton pregnancy in their first trimester. Women with a known fetal anomaly, hypertension (systolic $>160 \mathrm{~mm} \mathrm{Hg}$ or diastolic $>90 \mathrm{~mm} \mathrm{Hg}$ ), history of or current psychotic or eating disorder, human immunodeficiency virus, preexisting diabetes (self-report or determined by glycated hemoglobin $\mathrm{A}_{1 \mathrm{c}}$ and/or $75 \mathrm{~g}$ oral glucose tolerance test in the first trimester), or with contraindications to exercise (by PARmed-X and American College of Obstetricians and Gynecologists committee opinion \#67 [6]) were excluded. With support of local obstetricians, participants were recruited from brochures placed in various clinics and by study staff during the patients' first prenatal appointment [7]. Participants were randomized by unblinded intervention staff equally to one of three groups between 10.4 to 13.6 weeks of gestation: (1) no intervention (usual care group), (2) receipt of the SmartMoms intervention in-person (in-person group), or (3) receipt of the SmartMoms intervention via mobile phone (remote group), with randomization stratified by pregravid BMI. The block randomization schedule and sealed numbered randomization envelopes were prepared by the biostatistician. Usual care (control) participants were under the usual care of their obstetrician and did not receive weight management services from the intervention team. The SmartMoms intervention was designed to assist an expectant mother in gaining weight within the recommended 2009 IOM guidelines for her respective BMI class. SmartMoms is grounded in the ability to objectively quantify dietary adherence to an energy intake prescription based on measured body weight and to provide patients with data-driven feedback about their energy intake [8-12]. SmartMoms participants received dietary intake advice, exercise advice, and a weight graph created from the dynamic GWG models to determine the trimester-specific increase in energy intake required by each participant to adhere to the IOM GWG recommendations [13]. To promote these lifestyle changes, participants received a structured intervention that consisted of 18 lessons and behavior modification strategies. SmartMoms participants received behavior modification counseling weekly between weeks 13 and 24 of gestation and biweekly from week 25 until delivery. Importantly, the content of the lesson materials were identical and only the mode of delivery differed between the two intervention groups. Participants in both the intervention groups were provided with a wireless Internet-connected bathroom scale and a pedometer (in-person group: Omron Healthcare, Lake Forest, IL, USA; remote group: Fitbit Zip, FitBit, San Francisco, CA, USA) to self-monitor body weight and step counts daily. The mobile phone app is similar to a virtual weight management system described for weight loss in which body weight and daily steps are automatically transmitted in real time to personalized charts [14]. The SmartMoms intervention includes an IOM 2009 GWG weight graph personalized for each patient and behavioral modification tools including daily self-monitoring of weight, dietary intake, and physical activity [14]. SmartMoms participants were provided with an individualized calorie intake above their estimated prepregnancy energy requirement [13] or energy gap represented by an ideal weight gain zone [15], and were coached how to adjust energy intake and/or physical activity to adhere to the IOM 2009 GWG guidelines. The in-person group tracked step counts with pen and paper, and the IOM weight graph was reviewed in hard copy during counseling sessions with interventionists.

Clinic assessments were performed by certified staff who were blinded to group assignment. Maternal weight was measured fasting and in a hospital gown. Total GWG and GWG per week were calculated between the initial (10-13 weeks) and final (35-36 weeks) study visits. GWG per week was used to calculate the proportion of women based on prepregnancy BMI with recommended or excessive GWG per the 2009 IOM GWG guidelines [16].

Adherence to the SmartMoms intervention was defined as the percentage of days participants weighed and recorded step counts in comparison to the expected number of days. Study economics, including costs incurred for travel to and from treatment sessions and time spent with the counselor while accounting for session attendance and intervention adherence, were calculated for each participant. The clinic economics included cost of interventionist time (training, session preparation, participant contacts, routine staff meetings) and equipment (scale, pedometer) cost.

Statistical analyses were completed using SAS/STAT version 9.4 software of the SAS System for Windows (Cary, NC, USA). Sample size was based on the hypothesis that the proportion of overweight and obese pregnant women in the usual care group exceeding IOM guidelines for GWG would be $58 \%$ and that lowering this proportion by at least $25 \%$ would be clinically 
significant. Intention-to-treat comparison of continuous variables (eg, GWG, birth weight) between the three treatment groups used one-way analysis of variance with post hoc pairwise intervention group comparisons. Comparisons of categorical variables (eg, prevalence of excess GWG) between the three treatment groups used Fisher exact test. Equality of adherence to IOM GWG guidelines was tested through one-sided $\mathrm{z}$ tests for proportions. Finally, differences in study costs and intervention adherence were assessed through two-sample $t$ tests. All tests were performed with significance level alpha=.05, and findings were considered significant when $P<$ alpha. Data are reported as least square (LS) mean and standard error (SE) unless otherwise noted.

\section{Results}

Recruitment of participants from community clinics from February 1, 2013 to April 14, 2014, yielded three groups of pregnant women who were similar (Table 1). The majority of participants were white and nulliparous or primiparous. No study-related serious adverse events were reported.

\section{Gestational Weight Gain and Guideline Adherence}

The SmartMoms intervention (in-person and remote groups combined) was effective at reducing GWG in overweight and obese pregnant women (usual care: LS mean 12.8, SE $1.5 \mathrm{~kg}$; SmartMoms: LS mean 9.2, SE $0.9 \mathrm{~kg} ; P=.04)$. The in-person group gained significantly less total weight (Figure 1) during pregnancy than the usual care group (LS mean $8.0, \mathrm{SE} 1.3 \mathrm{~kg}$ vs LS mean 12.8 , SE $1.5 \mathrm{~kg} ; P=.04$ ) and weight gain in the remote group was equivalent to the in-person group (LS mean 10.0 , SE $1.3 \mathrm{~kg} ; P=.04$ equivalence) and modestly lower than weight gain with usual care (LS mean 10.0 , SE $1.2 \mathrm{~kg}$ vs LS mean 12.8 , SE $1.5 \mathrm{~kg} ; P=.07)$. Compared to usual care, the rate of GWG was significantly lower in the in-person group (LS mean 0.49, SE $0.06 \mathrm{~kg} /$ week vs LS mean 0.31, SE $0.05 \mathrm{~kg} /$ week; $P=.01$ ) and the rate of GWG in the in-person group was equivalent to the remote group (LS mean 0.39 , SE $0.05 \mathrm{~kg} /$ week; $P=.04)$ within 200 grams of weight gained per week. The proportion of women with excess GWG (Figure 2) was significantly lower in the in-person $(56 \%, 10 / 18 ; P=.03)$ and remote groups $(58 \%, 11 / 19 ; P=.04)$ compared to usual care $(84.6 \%, 11 / 13)$.

Table 1. Baseline characteristics by treatment group $(\mathrm{N}=54)$.

\begin{tabular}{|c|c|c|c|c|}
\hline Characteristic & Usual care $(n=17)$ & In-person $(\mathrm{n}=18)$ & Remote $(\mathrm{n}=19)$ & $P^{\mathrm{a}}$ \\
\hline Age (years), mean (SD) & $29.5(5.1)$ & $29.2(4.8)$ & $29.0(4.2)$ & .96 \\
\hline Race, $n(\%)$ & & & & .24 \\
\hline Black & $6(35)$ & $5(28)$ & $2(11)$ & \\
\hline White & $11(65)$ & $11(61)$ & $16(84)$ & \\
\hline Other & $0(0)$ & $2(11)$ & $1(5)$ & \\
\hline Weight $(\mathrm{kg})$, mean (SD) & $86.2(12)$ & $83.0(12)$ & $81.1(13)$ & .45 \\
\hline Parity, n (\%) & $0.6(1)$ & $0.7(1)$ & $0.9(1)$ & .54 \\
\hline Pregravid BMI group, n (\%) & & & & .84 \\
\hline Overweight $\left(25.0-29.9 \mathrm{~kg} / \mathrm{m}^{2}\right)$ & $9(53)$ & $8(44)$ & $8(42)$ & \\
\hline Obese $\left(30.0-40.0 \mathrm{~kg} / \mathrm{m}^{2}\right)$ & $8(47)$ & $10(56)$ & $11(58)$ & \\
\hline Family income per year (US\$), n (\%) & & & & .50 \\
\hline$<\$ 5000-\$ 39,999$ & $7(41)$ & $9(50)$ & $7(37)$ & \\
\hline$\$ 40,000-\$ 99,999$ & $5(29)$ & $7(39)$ & $5(26)$ & \\
\hline$\geq \$ 100,000$ & $5(29)$ & $2(11)$ & $7(37)$ & \\
\hline Education, $\mathbf{n}(\%)$ & & & & .24 \\
\hline Some high school & $0(0)$ & $1(6)$ & $0(0)$ & \\
\hline $\begin{array}{l}\text { High school diploma/GED/1-3 years of college, business, or } \\
\text { technical school }\end{array}$ & $7(41)$ & $5(28)$ & $6(32)$ & \\
\hline College degree & $4(24)$ & 7 (39) & $11(58)$ & \\
\hline Postgraduate work & $6(35)$ & $5(28)$ & $2(11)$ & \\
\hline
\end{tabular}

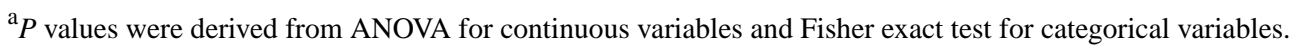


Figure 1. Mean gestational weight gain $(\mathrm{kg})$ for women in the usual care, remote, and in-person groups. The whiskers represent standard error.

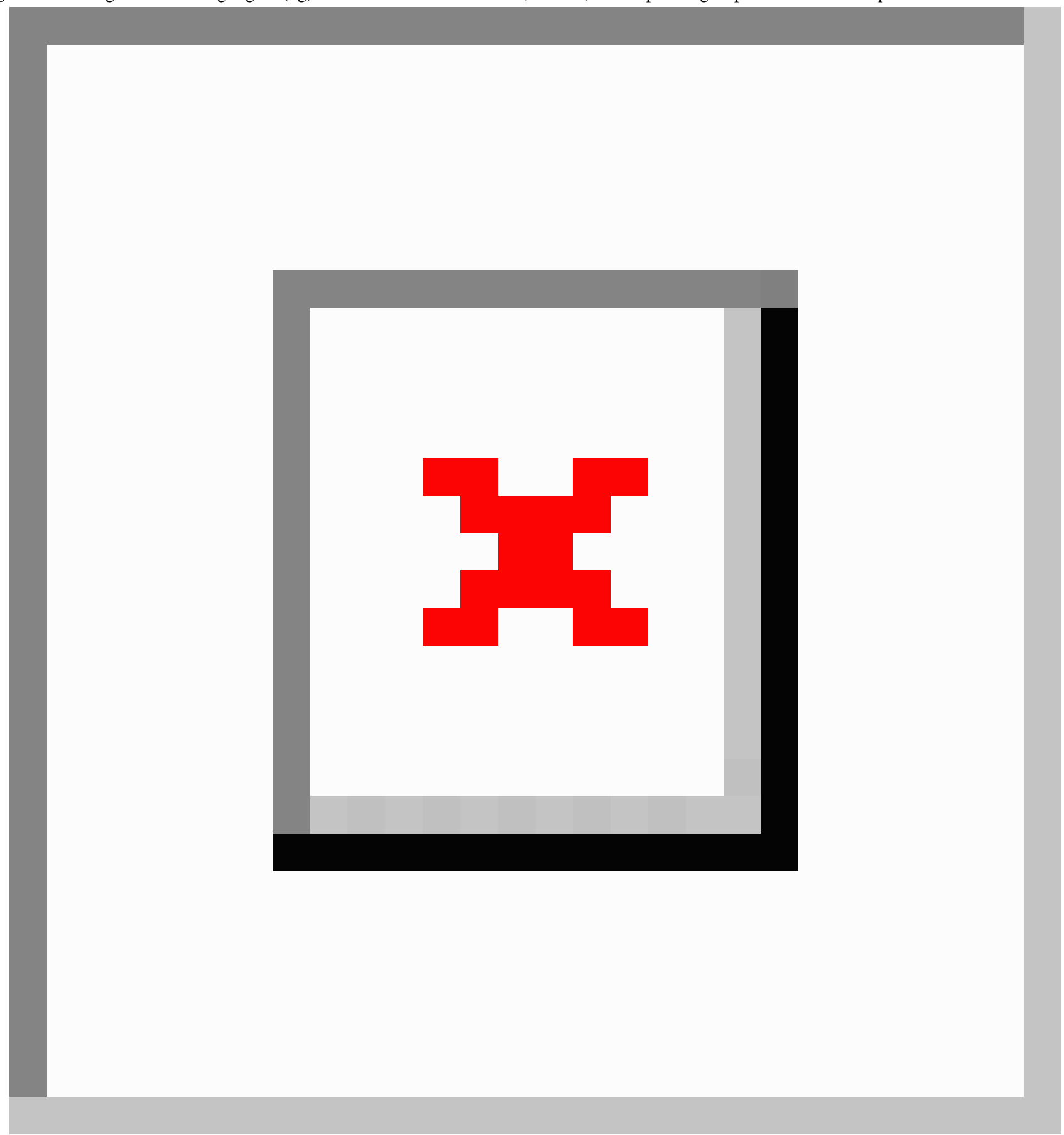


Figure 2. Proportion of women in the usual care, remote, and in-person groups who had appropriate and excess gestational weight gain (GWG) based on the IOM 2009 guidelines. *The SmartMoms intervention (in-person and remote groups combined) was effective at reducing GWG.

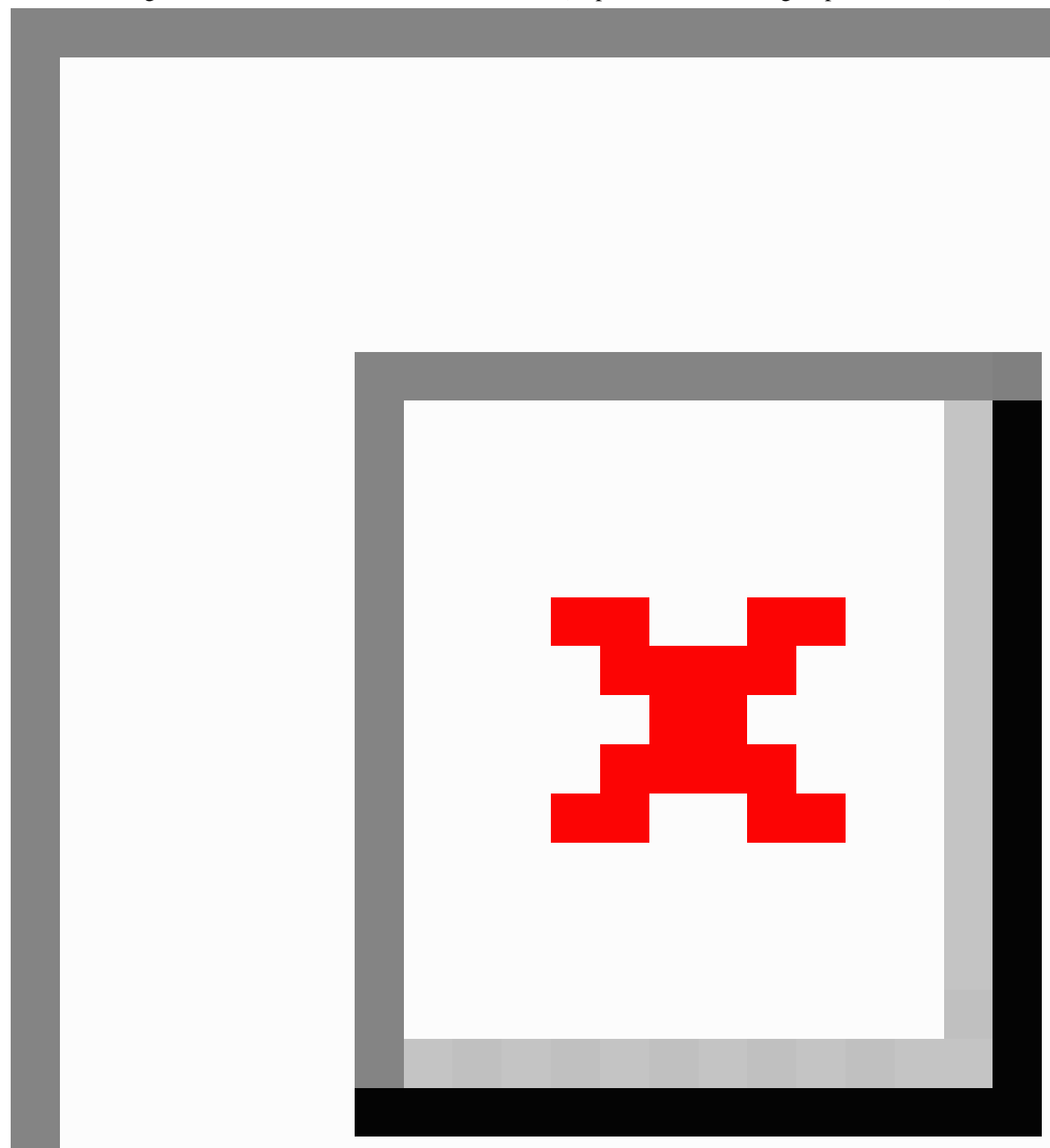

\section{Intervention Adherence and Study Economics}

The in-person group recorded weight and step data (weight: mean $57.2 \%$, SD $33.8 \%$; step: mean $44.5 \%$, SD $33.3 \%$ ) less often than the remote group (weight: mean $71.2 \%$, SD $24.1 \%$; step: mean 72.5, SD 29.0\%) and the in-person group attended mean $78 \%$ (SD 39\%) of planned behavioral sessions. Therefore, overall intervention adherence (Figure 3 ) was greater in the remote group than the in-person group $(76.5 \%$ vs $60.8 \%$; $P=.049$ ). The intervention cost (Figure 4) to a participant in the remote group was 3.5 times less than the cost for a participant in the in-person group (mean US \$97, SD \$6 vs mean US \$347, SD $\$ 40$ per participant; $P<.001)$. Similarly, the clinic cost to deploy the remote intervention was $50 \%$ less than the cost to deploy the in-person intervention (US \$215 vs US \$419 per participant). 
Figure 3. Intervention adherence for the remote and in-person groups. The whiskers represent standard error.

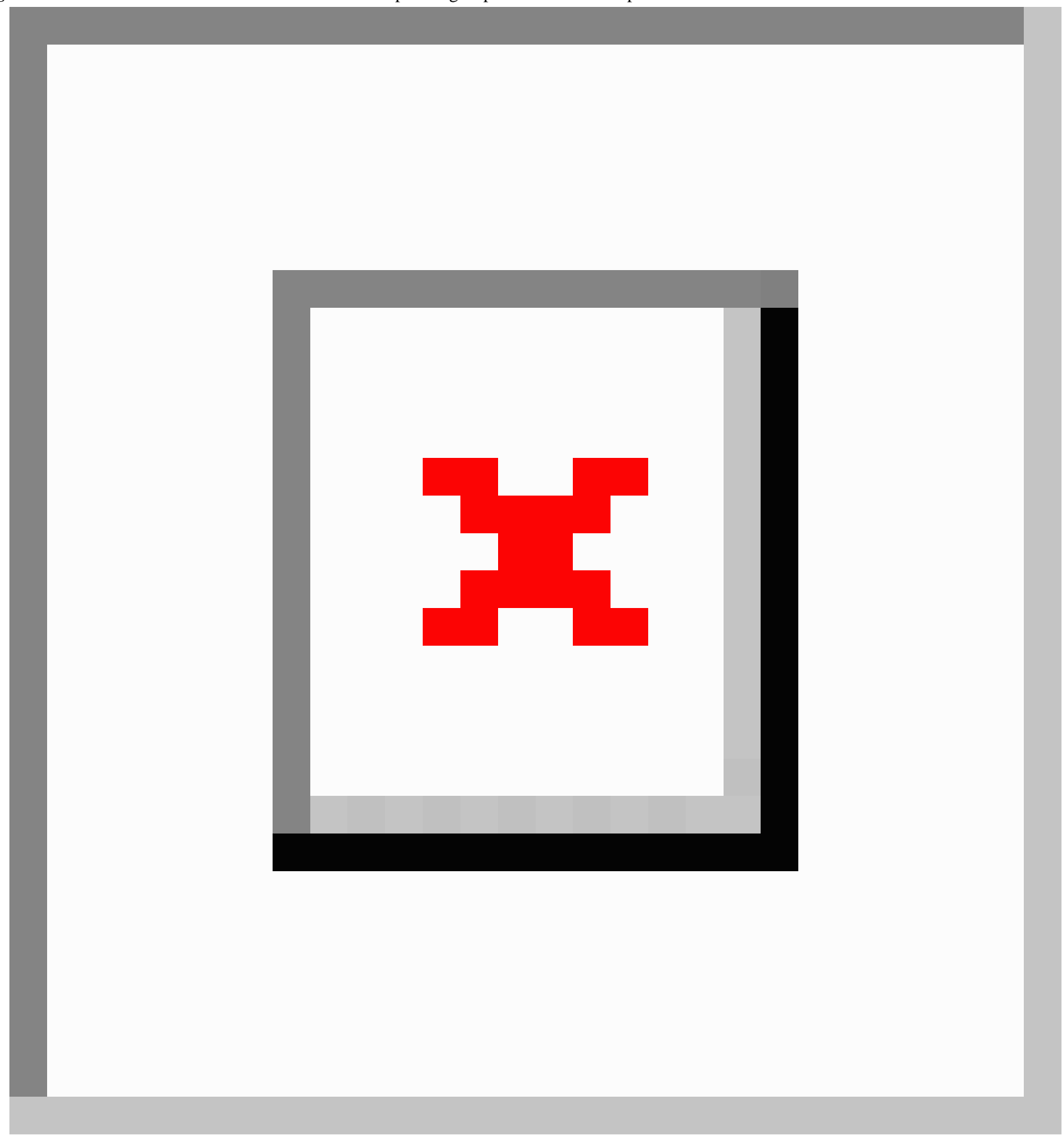


Figure 4. Mean intervention cost (US \$) for participants and clinics for the remote and in-person groups. The whiskers represent standard error. The intervention cost incurred by the clinic was fixed.

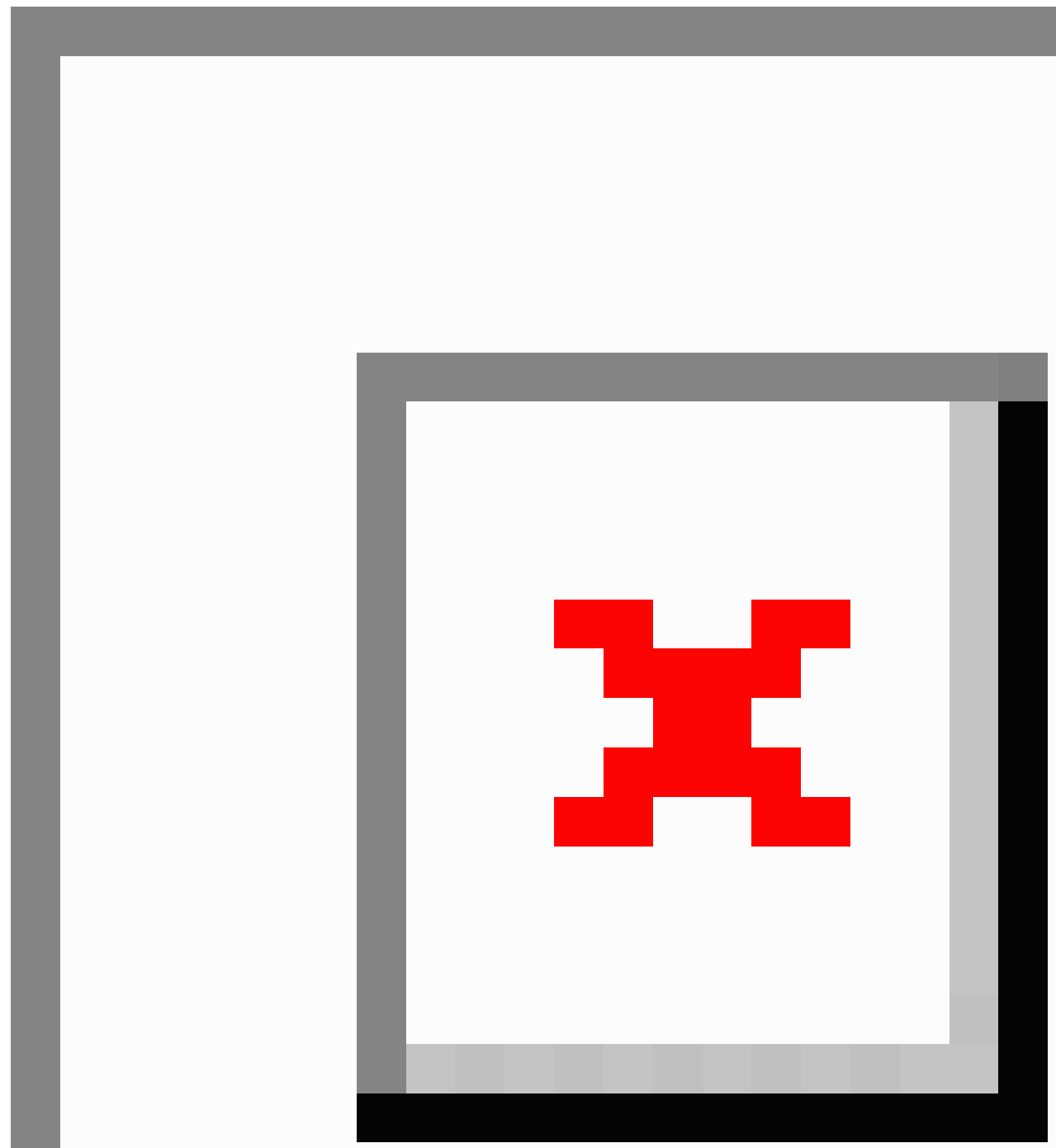

\section{Discussion}

Lifestyle interventions to improve adherence to the IOM GWG recommendations have had modest success in reducing GWG $[4,17]$ and little impact reducing the incidence of excess GWG [18]. The greatest success has been with a recommendation of caloric restriction [19]; however, due to popular beliefs such as the need to "eat for two" [20], caloric restriction is not widely accepted among patients, practitioners, or their support systems. Albeit in a small sample, we attribute the success of the SmartMoms intervention to its early initiation (13 weeks gestation) and intervention intensiveness being commensurate with weight management treatment for nonpregnant individuals including self-monitoring with timely feedback, a dietary prescription to foster optimal weight change, and receipt of structured behavior change intervention through delivery of 18 lessons over a 24-week interval beginning at the second trimester.

When deployed remotely through a mobile phone, the SmartMoms intervention was just as effective at reducing the proportion of excess GWG when delivered in-person; however, it was found to be at least $50 \%$ more economical for patients and providers with a higher level of patient engagement or adherence. This eHealth intervention, including the provision of a personalized IOM GWG weight graph through Internet-connected devices, easily disseminates supportive health 
information to patients, and remote patient communication provides an ideal framework for integration into an electronic health record system. Using estimates of interventionist time recorded throughout the study, it is estimated that approximately 30 to 50 new patients per clinician per month could be monitored simultaneously through the remote program by a single health care provider, such as a dietician or lifestyle coach, for universal delivery to all patients within a clinical practice. Similar telehealth services are covered by health care insurance companies, including Medicaid, and are already used by health care facilities across the United States such as in the Veterans Affairs Hospital System for management of chronic health conditions [21]. The SmartMoms mobile phone intervention tested on community-based obstetrical patients could easily be integrated into standard clinical practice, thereby improving access to effective and efficient health care for millions of American women throughout the entire prenatal care continuum.

\section{Acknowledgments}

We thank the LIFE-Moms consortium members for their contributions to the development and oversight of the common measures and procedures shared across the trials. We also thank numerous local obstetrician gynecologists who allowed us to recruit patients in their clinics and the study participants who dedicated their time to this research.

Funding was received through National Institutes of Health grants U01 DK094418 (LMR), 1 U54 GM104940 (LAG, JHB, JWA), P30 DK072476, and F31 HD084199 (EFS). This study (U01 DK094418) is part of the National Institutes of Health Lifestyle Interventions in Expectant Moms (LIFE-Moms) Consortium. LIFE-Moms is supported by the National Institutes of Health through the National Institute of Diabetes and Digestive and Kidney Diseases (U01 DK094418, U01 DK094463, U01 DK094416, 5U01 DK094466 [RCU]), the National Heart, Lung, and Blood Institute (U01 HL114344, U01 HL114377), the Eunice Kennedy Shriver National Institute of Child Health and Human Development (U01 HD072834), the National Center for Complementary and Integrative Health (NCCIH), the NIH Office of Research in Women's Health (ORWH), the Office of Behavioral and Social Science Research (OBSSR), the Indian Health Service, and the Intramural Research Program of the NIDDK. This study was also supported in part by U54 GM104940 from the National Institute of General Medical Sciences of the National Institutes of Health, which funds the Louisiana Clinical and Translational Science Center. The content is solely the responsibility of the authors and does not necessarily represent the official views of the National Institutes of Health.

\section{Authors' Contributions}

LMR, CKM, and KEH designed the study. EFS, LEC, ADA, JB, and DH collected outcome data. LAG, JWA, SR, HB, AD, TS, and CKM conducted the interventions. JHB and JMT conducted analysis. LMR and LAG wrote the manuscript. All authors reviewed and approved the final draft.

\section{Conflicts of Interest}

Drs Redman, Martin, and Thomas developed the trademarked approach of SmartMoms (a registered trademark of the Louisiana State University System). There are no direct benefits to these authors for publication of this manuscript and they have no financial affiliations with the companies who conducted the work to develop the SmartMoms Virtual Weight Management Suite, although they could financially benefit from any licensing of SmartMoms along with LSU-Pennington Biomedical Research Center and Montclair State University. All other authors have no conflicts of interest to declare.

\section{Multimedia Appendix 1}

CONSORT-EHEALTH checklist (v1.6.1).

[PDF File (Adobe PDF File), 596KB-Multimedia Appendix 1]

\section{References}

1. Institute of Medicine and National Research Council Committee to Reexamine IOM Pregnancy Weight Guidelines. In: Rasmussen KM, Yaktine AL, editors. Weight Gain During Pregnancy: Reexamining the Guidelines. Washington, DC: National Academies Press; 2009.

2. Jensen M, Ryan DH, Apovian CM, Ard JD, Comuzzie AG, Donato KA, American College of Cardiology/American Heart Association Task Force on Practice Guidelines, Obesity Society. 2013 AHA/ACC/TOS guideline for the management of overweight and obesity in adults: a report of the American College of Cardiology/American Heart Association Task Force on Practice Guidelines and The Obesity Society. J Am Coll Cardiol 2014 Jul 01;63(25 Pt B):2985-3023. [doi: 10.1016/j.jacc.2013.11.004] [Medline: 24239920]

3. Flynn A, Dalrymple K, Barr S, Poston L, Goff LM, Rogozińska E, i-WIP (International Weight Management in Pregnancy) Collaborative Group. Dietary interventions in overweight and obese pregnant women: a systematic review of the content, delivery, and outcomes of randomized controlled trials. Nutr Rev 2016 May;74(5):312-328. [doi: 10.1093/nutrit/nuw005] [Medline: 27083868] 
4. Oteng-Ntim E, Varma R, Croker H, Poston L, Doyle P. Lifestyle interventions for overweight and obese pregnant women to improve pregnancy outcome: systematic review and meta-analysis. BMC Med 2012 May 10;10:47 [FREE Full text] [doi: 10.1186/1741-7015-10-47] [Medline: 22574949]

5. Childbirth Connection. How Do US Women Use the Internet and Other Sources of Pregnancy Information? A Listening to Mothers III Data Brief. 2016. URL: http://transform.childbirthconnection.org/wp-content/uploads/2013/05/ LTMIII-DB-infosources.pdf [accessed 2017-08-30] [WebCite Cache ID 6t6jNuEML]

6. ACOG Committee Obstetric Practice. ACOG Committee opinion. Number 267, January 2002: exercise during pregnancy and the postpartum period. Obstet Gynecol 2002 Jan;99(1):171-173. [Medline: 11777528]

7. Sutton E, Cain LE, Vallo PM, Redman LM. Strategies for successful recruitment of pregnant patients into clinical trials. Obstet Gynecol 2017 Mar;129(3):554-559. [doi: 10.1097/AOG.0000000000001900] [Medline: 28178062]

8. Pieper C, Redman L, Racette S, Roberts S, Bhapkar M, Rochon J, et al. Development of adherence metrics for caloric restriction interventions. Clin Trials 2011 Apr;8(2):155-164 [FREE Full text] [doi: 10.1177/1740774511398369] [Medline: 21385788]

9. Thomas DM, Ciesla A, Levine JA, Stevens JG, Martin CK. A mathematical model of weight change with adaptation. Math Biosci Eng 2009 Oct;6(4):873-887 [FREE Full text] [Medline: 19835433]

10. Thomas D, Das SK, Levine JA, Martin CK, Mayer L, McDougall A, et al. New fat free mass - fat mass model for use in physiological energy balance equations. Nutr Metab (Lond) 2010 May 09;7:39 [FREE Full text] [doi:

10.1186/1743-7075-7-39] [Medline: 20459692]

11. Thomas DM, Martin CK, Heymsfield S, Redman LM, Schoeller DA, Levine JA. A simple model predicting individual weight change in humans. J Biol Dyn 2011 Nov;5(6):579-599 [FREE Full text] [doi: 10.1080/17513758.2010.508541] [Medline: 24707319]

12. Thomas DM, Schoeller DA, Redman LA, Martin CK, Levine JA, Heymsfield SB. A computational model to determine energy intake during weight loss. Am J Clin Nutr 2010 Dec;92(6):1326-1331 [FREE Full text] [doi: 10.3945/ajcn.2010.29687] [Medline: 20962159]

13. Thomas DM, Navarro-Barrientos JE, Rivera DE, Heymsfield SB, Bredlau C, Redman LM, et al. Dynamic energy-balance model predicting gestational weight gain. Am J Clin Nutr 2012 Jan;95(1):115-122 [FREE Full text] [doi: 10.3945/ajen.111.024307] [Medline: 22170365]

14. Martin C, Gilmore LA, Apolzan JW, Myers CA, Thomas DM, Redman LM. Smartloss: a personalized mobile health intervention for weight management and health promotion. JMIR Mhealth Uhealth 2016 Mar 16;4(1):e18 [FREE Full text] [doi: 10.2196/mhealth.5027] [Medline: 26983937]

15. Hill J, Peters JC, Wyatt HR. Using the energy gap to address obesity: a commentary. J Am Diet Assoc 2009 Nov;109(11):1848-1853 [FREE Full text] [doi: 10.1016/j.jada.2009.08.007] [Medline: 19857625]

16. Gilmore LA, Redman LM. Weight gain in pregnancy and application of the 2009 IOM guidelines: toward a uniform approach. Obesity (Silver Spring) 2015 Mar;23(3):507-511 [FREE Full text] [doi: 10.1002/oby.20951] [Medline: 25521748]

17. Dodd J, Grivell RM, Crowther CA, Robinson JS. Antenatal interventions for overweight or obese pregnant women: a systematic review of randomised trials. BJOG 2010 Oct;117(11):1316-1326 [FREE Full text] [doi: 10.1111/j.1471-0528.2010.02540.x] [Medline: 20353459]

18. Kinnunen TI, Pasanen M, Aittasalo M, Fogelholm M, Hilakivi-Clarke L, Weiderpass E, et al. Preventing excessive weight gain during pregnancy - a controlled trial in primary health care. Eur J Clin Nutr 2007 Jul;61(7):884-891. [doi: 10.1038/sj.ejcn.1602602] [Medline: 17228348]

19. Vesco K, Karanja N, King JC, Gillman MW, Leo MC, Perrin N, et al. Efficacy of a group-based dietary intervention for limiting gestational weight gain among obese women: a randomized trial. Obesity (Silver Spring) 2014 Sep;22(9):1989-1996 [FREE Full text] [doi: 10.1002/oby.20831] [Medline: 25164259]

20. Kim LP, Koleilat M, Whaley SE. A qualitative study to examine perceptions and barriers to appropriate gestational weight gain among participants in the Special Supplemental Nutrition Program for Women Infants and Children Program. J Pregnancy 2016;2016:4569742 [FREE Full text] [doi: 10.1155/2016/4569742] [Medline: 27403341]

21. Benton S. Hospitals and Health Networks. 2016 Mar 3. Four reasons why telemedicine can improve patient engagement URL: http://www.hhnmag.com/articles/6974-telemedicine-to-improve-patient-engagement [accessed 2017-08-11] [WebCite Cache ID 6sjhXDWJe]
Abbreviations
BMI: body mass index
GWG: gestational weight gain
IOM: Institute of Medicine 
Edited by G Eysenbach; submitted 16.06.17; peer-reviewed by D Downs, A Rickman; comments to author 13.07.17; revised version received 27.07.17; accepted 29.07.17; published 13.09.17

Please cite as:

Redman LM, Gilmore LA, Breaux J, Thomas DM, Elkind-Hirsch K, Stewart T, Hsia DS, Burton J, Apolzan JW, Cain LE, Altazan AD, Ragusa S, Brady H, Davis A, Tilford JM, Sutton EF, Martin CK

Effectiveness of SmartMoms, a Novel eHealth Intervention for Management of Gestational Weight Gain: Randomized Controlled Pilot Trial

JMIR Mhealth Uhealth 2017;5(9):e133

URL: http://mhealth.jmir.org/2017/9/e133/

doi: $10.2196 /$ mhealth. 8228

PMID: 28903892

(CLeanne M Redman, L. Anne Gilmore, Jeffrey Breaux, Diana M Thomas, Karen Elkind-Hirsch, Tiffany Stewart, Daniel S Hsia, Jeffrey Burton, John W Apolzan, Loren E Cain, Abby D Altazan, Shelly Ragusa, Heather Brady, Allison Davis, J. Mick Tilford, Elizabeth F Sutton, Corby K Martin. Originally published in JMIR Mhealth and Uhealth (http://mhealth.jmir.org), 13.09.2017. This is an open-access article distributed under the terms of the Creative Commons Attribution License (https://creativecommons.org/licenses/by/4.0/), which permits unrestricted use, distribution, and reproduction in any medium, provided the original work, first published in JMIR mhealth and uhealth, is properly cited. The complete bibliographic information, a link to the original publication on http://mhealth.jmir.org/, as well as this copyright and license information must be included. 